\title{
BMJ Open The use of the reverse shock index to identify high-risk trauma patients in addition to the criteria for trauma team activation: a cross-sectional study based on a trauma registry system
}

\author{
Spencer C H Kuo, ${ }^{1,2}$ Pao-Jen Kuo, ${ }^{3}$ Shiun-Yuan Hsu, ${ }^{1,2}$ Cheng-Shyuan Rau, ${ }^{4}$ \\ Yi-Chun Chen, ${ }^{1,2}$ Hsiao-Yun Hsieh, ${ }^{1,2}$ Ching-Hua Hsieh ${ }^{1,2}$
}

To cite: Kuo SCH, Kuo P-J, Hsu S-Y, et al. The use of the reverse shock index to identify high-risk trauma patients in addition to the criteria for trauma team activation: a cross-sectional study based on a trauma registry system. BMJ Open 2016;6:e011072.

doi:10.1136/bmjopen-2016011072

- Prepublication history and additional material is available. To view please visit the journal (http://dx.doi.org/ 10.1136/bmjopen-2016011072).

Received 7 January 2016 Revised 26 May 2016 Accepted 27 May 2016

CrossMark

For numbered affiliations see end of article.

Correspondence to Dr Ching-Hua Hsieh; m93chinghua@gmail.com

\section{ABSTRACT}

Objectives: The presentation of decrease blood pressure with tachycardia is usually an indicator of significant blood loss. In this study, we used the reverse shock index (RSI), a ratio of systolic blood pressure (SBP) to heart rate (HR), to evaluate the haemodynamic status of trauma patients. As an SBP lower than the $\mathrm{HR}(\mathrm{RSI}<1)$ may indicate

haemodynamic instability, the objective of this study was to assess whether RSI $<1$ can help to identify highrisk patients with potential shock and poor outcome, even though these patients do not yet meet the criteria for multidisciplinary trauma team activation (TTA).

Design: Cross-sectional study.

Setting: Taiwan.

Participants: We retrospectively reviewed the data of 20106 patients obtained from the trauma registry system of a level I trauma centre for trauma admissions from January 2009 through December 2014. Patients for whom a trauma team was not activated (regular patients) and who had $\mathrm{RS} \mid<1$ were compared with regular patients with $\mathrm{RSI} \geq 1$. The $\mathrm{ORs}$ of the associated conditions and injuries were calculated with $95 \% \mathrm{Cls}$.

Main outcome measures: In-hospital mortality. Results: Among regular patients with $\mathrm{RSI}<1$, significantly more patients had an Injury Severity Score (ISS) $\geq 25$ (OR 2.4, 95\% Cl 1.58 to $3.62 ; p<0.001$ ) and the mortality rate was also higher $(2.1 \%$ vs $0.5 \%$; OR $3.9,95 \% \mathrm{Cl} 2.10$ to $7.08 ; p<0.001$ ) than in regular patients with $R S I \geq 1$. The intensive care unit length of stay was longer in regular patients with $\mathrm{RSI}<1$ than in regular patients with $\mathrm{RSI} \geq 1$.

Conclusions: Among patients who did not reach the criteria for TTA, RSI $<1$ indicates a potentially worse outcome and a requirement for more attention and aggressive care in the emergency department.

\section{INTRODUCTION}

Trauma patients present to the emergency department (ED) with a great variety of

\section{Strengths and limitations of this study}

- This study proposes that systolic blood pressure (SBP) lower than heart rate (HR) (ie, reverse shock index $(\mathrm{RSI})<1$ ) in trauma patients suggests an unstable haemodynamic status and a poor outcome.

- The addition of $\mathrm{RSI}<1$ to the criteria for trauma team activation may be justified but would result in overtriage and longer hospital stay.

- Injured patients who died before arrival at hospital or who were discharged against advice from the emergency department were excluded, which may have been a source of bias.

- Lack of data on the circumstances of injury, factors influencing decision making, patients' underlying diseases and medication use may have also been sources of bias.

injuries and diseases. As the most important task is to quickly and accurately identify those patients at greatest risk, triage is employed in order to improve patient outcome and minimise wastage of ED resources. ${ }^{1-3}$ In addition, activation of a multidisciplinary trauma team (trauma team activation, TTA) to assess and treat seriously injured patients has been shown to improve health outcomes. ${ }^{4-7}$ The trauma team usually comprises members of different specialties, including an emergency physician, a surgeon, an anaesthesiologist, a radiologist, a nurse and support staff, all of whom help assess and manage the trauma patient. A single team trauma response or a tiered-response TTA is used depending on policy and requirements.

Significant bleeding is a major cause of morbidity and mortality in seriously injured patients, ${ }^{8}$ so the vital signs of the patient, 
including heart rate (HR) and blood pressure, are usually monitored. Moreover, tachycardia together with hypotension is usually an indication of blood loss and identifies haemorrhagic shock. However, tachycardia does not always accompany haemorrhagic shock in trauma patients, and the correlation between tachycardia and hypotension maybe poor and misleading according to previous studies. ${ }^{9-13}$

The ratio of HR to systolic blood pressure (SBP), the shock index (SI), has been shown to be useful in predicting mortality rates in trauma patients, ${ }^{14}{ }^{15}$ and may be useful in detecting early acute hypovolemia. ${ }^{16}$ Cannon et $\mathrm{l}^{17}$ reported that trauma patients with $\mathrm{SI}>0.9$ have higher mortality rates, and that an increase in the SI from the field to the ED may predict higher mortality. Mitra $e t a l^{18}$ found that patients with $\mathrm{SI} \geq 1.0$ have significantly higher transfusion requirements and higher mortality rates than major trauma patients in general, despite prehospital crystalloid resuscitation. A retrospective study using multiple logistic regression demonstrated that $\mathrm{SI}>1$ is an independent predictor of death. ${ }^{19}$ Previous studies have also shown that SI is correlated with duration of hospital stay, duration of stay in the intensive care unit (ICU), number of ventilator days, and blood product use. ${ }^{15}{ }^{20}$ However, evaluation of haemodynamic instability is based on the presence of hypotension, which may cause concern if SBP is lower than HR, instead of HR being higher than SBP $($ ie, SI $>1){ }^{21}$ Therefore, calculation of SI as the ratio of HR to SBP seems to conflict with the basic concept of shock. In our opinion, checking if SBP is lower than HR may help identify patients with potential shock and a poor outcome. Consequently, we introduce the ratio of SBP to HR as the reverse SI (RSI) to be used with TTA criteria to identify high-risk trauma patients with haemodynamic instability and a poor outcome.

\section{METHODS}

This study was approved by the institutional review board (IRB) of Kaohsiung Chang Gung Memorial Hospital, a 2400-bed facility and level I trauma centre that provides care to trauma patients primarily from South Taiwan. Informed consent was not required under IRB regulations. A retrospective study was designed to review all patients $(n=20106)$ whose data were entered into the trauma registry system between 1 January 2009 and 31 December 2014. Detailed patient information was retrieved from the trauma registry system of our institution including data on age, sex, vital signs and RSI on arrival, procedures performed in the $\mathrm{ED}$, presence or absence of TTA, injury mechanism, blood alcohol concentration (BAC) on arrival, Injury Severity Score (ISS), hospital length of stay (LOS), ICU LOS, in-hospital mortality, and associated trauma in each body region.

In our hospital the trauma team is activated when the patient meets one of the following established criteria: (i) Glasgow Coma Scale score $\leq 10$; (ii) $\mathrm{SBP} \leq 90 \mathrm{~mm} \mathrm{Hg}$; (iii) respiratory rate $\geq 30 / \mathrm{min}$ or $<10 / \mathrm{min}$; (iv) fall from a height of $\geq 6 \mathrm{~m}$ or from two stories up; or (v) severe multiple injuries requiring TTA as decided by on-site physicians. To evaluate the need to add $\mathrm{RSI}<1$ to the TTA criteria, patients for whom a trauma team was not activated (ie, regular patients) but who had $\mathrm{RSI}<1$ $(\mathrm{n}=585,2.9 \%)$ were compared with regular patients with $\mathrm{RSI} \geq 1 \quad(\mathrm{n}=17407,86.6 \%)$, and with those for whom a trauma team was activated $(\mathrm{n}=2114,10.5 \%)$. SPSS V.20 statistical software (IBM, Armonk, New York, USA) was used. The main outcome measure was in-hospital mortality. For categorical variables, $\chi^{2}$ tests were used to determine the significance of associations between the predictor and outcome variables. For continuous variables, Student's t-tests were applied to evaluate the significance of associations between the predictor and outcome variables. Univariate logistic regression analyses were initially performed to identify the significant predictor variables of the injury or mortality risk. The corresponding unadjusted ORs with 95\% CIs for each variable were obtained. We also estimated the adjusted ORs (aORs) and 95\% CIs for mortality through stepwise model selection of a multiple regression model that was adjusted by controlling for the confounding variables age and ISS. All results are presented as the mean \pm SE. A $p$ value $<0.05$ was considered statistically significant.

\section{RESULTS}

The demographic data and clinical features of the patients enrolled in this study are summarised in table 1. The mean RSIs were $0.8 \pm 0.1,1.8 \pm 0.5$ and $1.5 \pm 0.7$ in regular patients with $\mathrm{RSI}<1$, regular patients with $\mathrm{RSI} \geq 1$ and TTA patients, respectively. Overall, $348(59.5 \%)$ of the regular patients with $\mathrm{RSI}<1$ were aged $0-9$ years, while most of the regular patients with $\mathrm{RSI} \geq 1$ and the TTA patients were aged $20-79$ years $(79.4 \%$ and $83.5 \%$, respectively). As regards mechanism of injury, motorcycle accidents, falls and being struck by/striking an object accounted for most cases in all three groups of patients. Among regular patients with $\mathrm{RSI}<1,241$ $(41.2 \%)$ were struck by/struck an object, 173 (29.6\%) experienced a fall, and $92(15.7 \%)$ had motorcycle accidents. However, among regular patients with $\mathrm{RSI} \geq 1$ and TTA patients, $6759(38.8 \%)$ and $1014(48.0 \%)$, respectively, had motorcycle accidents, while $5409(31.1 \%)$ and $476(22.5 \%)$, respectively, experienced a fall. The mean BAC levels were $138.1 \pm 84.7, \quad 155.1 \pm 94.6$ and 165.4 $\pm 98.5 \mathrm{mg} / \mathrm{dL}$ for patients in the three groups, respectively. More regular patients with $\mathrm{RSI}<1$ than regular patients with $\mathrm{RSI} \geq 1$ had a BAC level $\geq 50 \mathrm{mg} / \mathrm{dL}$ (OR $1.5,95 \%$ CI 1.05 to $2.16 ; \mathrm{p}=0.025)$, but fewer regular patients with $\mathrm{RSI}<1$ than TTA patients had a BAC level $\geq 50 \mathrm{mg} / \mathrm{dL}$ (OR $0.3,95 \%$ CI 0.19 to $0.39 ; \mathrm{p}<0.001$ ). Most regular patients with $\mathrm{RSI}<1$ and regular patients with $\mathrm{RSI} \geq 1$ were moderately injured (ISS $<15$ ). However, significantly more patients were very severely injured 
Table 1 Demographic data of the hospitalised trauma patients

\begin{tabular}{|c|c|c|c|c|c|c|c|}
\hline \multirow[b]{2}{*}{ Variable } & \multirow{2}{*}{$\begin{array}{l}\text { Regular patients } \\
\text { with } R S \mid<1 \\
n=585\end{array}$} & \multirow{2}{*}{$\begin{array}{l}\text { Regular patients } \\
\text { with } R S I \geq 1 \\
n=17407\end{array}$} & \multirow{2}{*}{$\begin{array}{l}\text { TTA patients } \\
\mathrm{n}=2114\end{array}$} & \multicolumn{2}{|c|}{$\begin{array}{l}\text { Regular patients with } \mathrm{RSI}<1 \text { vs } \\
\text { regular patients with } \mathrm{RSI} \geq 1\end{array}$} & \multicolumn{2}{|c|}{$\begin{array}{l}\text { Regular patients } \\
\text { with } \mathrm{RSI}<1 \text { vs TTA patients }\end{array}$} \\
\hline & & & & OR (95\% Cl) & p Value & OR $(95 \% \mathrm{Cl})$ & p Value \\
\hline \multicolumn{8}{|l|}{ RSI } \\
\hline Mean & $0.8 \pm 0.1$ & $1.8 \pm 0.5$ & $1.5 \pm 0.7$ & - & $<0.001$ & - & $<0.001$ \\
\hline Range & $0.0-0.9$ & $1.0-9.5$ & 0.08 .5 & - & - & - & - \\
\hline \multicolumn{8}{|l|}{ Gender } \\
\hline Male & $340(58.1)$ & 9905 (56.9) & $1424(67.4)$ & $1.1(0.89$ to 1.24$)$ & 0.581 & 0.7 (0.56 to 0.81$)$ & $<0.001$ \\
\hline Female & 245 (41.9) & 7502 (43.1) & $690(32.6)$ & $1.0(0.81$ to 1.12$)$ & 0.581 & 1.5 (1.23 to 1.79$)$ & $<0.001$ \\
\hline Age (years) & $18.5 \pm 23.7$ & $47.8 \pm 22.3$ & $46.0 \pm 21.0$ & - & $<0.001$ & - & $<0.001$ \\
\hline 0-9 & $348(59.5)$ & $576(3.3)$ & $64(3.0)$ & $42.9(35.67$ to 51.61$)$ & $<0.001$ & 47.0 (34.89 to 63.40$)$ & $<0.001$ \\
\hline $10-19$ & $41(7.0)$ & $1579(9.1)$ & $158(7.5)$ & $0.8(0.55$ to 1.04$)$ & 0.095 & $0.9(0.65$ to 1.33$)$ & 0.789 \\
\hline $20-29$ & $50(8.5)$ & $2376(13.6)$ & $343(16.2)$ & 0.6 (0.44 to 0.79$)$ & $<0.001$ & 0.5 (0.35 to 0.66$)$ & $<0.001$ \\
\hline 30-39 & $41(7.0)$ & $2004(11.5)$ & 293 (13.9) & 0.6 (0.42 to 0.80$)$ & 0.001 & 0.5 (0.33 to 0.66$)$ & $<0.001$ \\
\hline $40-49$ & $24(4.1)$ & 2174 (12.5) & $325(15.4)$ & 0.3 (0.20 to 0.45$)$ & $<0.001$ & $0.2(0.15$ to 0.36$)$ & $<0.001$ \\
\hline $50-59$ & $28(4.8)$ & 2832 (16.3) & $340(16.1)$ & $0.3(0.18$ to 0.38$)$ & $<0.001$ & 0.3 (0.18 to 0.39$)$ & $<0.001$ \\
\hline $60-69$ & $14(2.4)$ & $2438(14.0)$ & $249(11.8)$ & 0.2 (0.09 to 0.26$)$ & $<0.001$ & 0.2 (0.11 to 0.32$)$ & $<0.001$ \\
\hline 70-79 & $21(3.6)$ & $2006(11.5)$ & $214(10.1)$ & 0.3 (0.18 to 0.44$)$ & $<0.001$ & 0.3 (0.21 to 0.52$)$ & $<0.001$ \\
\hline 80-89 & $17(2.9)$ & $1240(7.1)$ & $107(5.1)$ & 0.4 (0.24 to 0.63$)$ & $<0.001$ & 0.6 (0.33 to 0.94$)$ & 0.026 \\
\hline$\geq 90$ & $1(0.2)$ & $182(1.0)$ & $21(1.0)$ & $0.2(0.02$ to 1.16$)$ & 0.054 & $0.2(0.02$ to 1.27$)$ & 0.065 \\
\hline \multicolumn{8}{|l|}{ Mechanism } \\
\hline Driver of MV & $9(1.5)$ & 207 (1.2) & 67 (3.2) & 1.3 (0.66 to 2.54$)$ & 0.436 & 0.5 (0.24 to 0.96$)$ & 0.034 \\
\hline Passenger of MV & $6(1.0)$ & $121(0.7)$ & $41(1.9)$ & 1.5 (0.65 to 3.37$)$ & 0.311 & 0.5 (0.22 to 1.24$)$ & 0.155 \\
\hline Motorcycle driver & $92(15.7)$ & $6759(38.8)$ & $1014(48.0)$ & 0.3 (0.24 to 0.37$)$ & $<0.001$ & $0.2(0.16$ to 0.26$)$ & $<0.001$ \\
\hline Motorcycle pillion passenger & $29(5.0)$ & $483(2.8)$ & $85(4.0)$ & 1.8 (1.25 to 2.68$)$ & 0.002 & $1.2(0.81$ to 1.92$)$ & 0.352 \\
\hline Bicycle & $22(3.8)$ & $710(4.1)$ & $76(3.6)$ & 0.9 (0.60 to 1.42$)$ & 0.820 & 1.0 (0.65 to 1.70$)$ & 0.804 \\
\hline Pedestrian & $13(2.2)$ & $299(1.7)$ & $68(3.2)$ & $1.3(0.74$ to 2.28$)$ & 0.333 & 0.7 (0.38 to 1.25$)$ & 0.272 \\
\hline Fall & $173(29.6)$ & 5409 (31.1) & $476(22.5)$ & $0.9(0.78$ to 1.12$)$ & 0.467 & 1.4 (1.18 to 1.77$)$ & 0.001 \\
\hline Unspecified & 241 (41.2) & 3419 (19.6) & $287(13.6)$ & 2.9 (2.42 to 3.39$)$ & $<0.001$ & 4.5 (3.63 to 5.48$)$ & $<0.001$ \\
\hline $\mathrm{BAC} \geq 50 \mathrm{mg} / \mathrm{dL}$ & $33(5.6)$ & $664(3.8)$ & 387 (18.3) & 1.5 (1.05 to 2.16$)$ & 0.025 & 0.3 (0.19 to 0.39$)$ & $<0.001$ \\
\hline \multicolumn{8}{|l|}{ BAC (mg/dL) } \\
\hline Mean & $138.1 \pm 84.7$ & $155.1 \pm 94.6$ & $165.4 \pm 98.5$ & - & 0.255 & - & 0.054 \\
\hline Range & $1.0-290.3$ & $0.2-414.6$ & $0.5-443.1$ & - & - & - & - \\
\hline ISS & $7.1 \pm 7.3$ & $7.3 \pm 5.4$ & $16.7 \pm 12.1$ & - & 0.340 & - & $<0.001$ \\
\hline $1-8$ & $370(63.2)$ & $9587(55.1)$ & $444(21.0)$ & 1.4 (1.18 to 1.67$)$ & $<0.001$ & 6.5 (5.31 to 7.89$)$ & $<0.001$ \\
\hline $9-15$ & $136(23.2)$ & $6203(35.6)$ & $568(26.9)$ & $0.5(0.45$ to 0.66$)$ & $<0.001$ & 0.8 (0.67 to 1.02$)$ & 0.079 \\
\hline $16-24$ & $54(9.2)$ & $1298(7.5)$ & $589(27.9)$ & 1.3 (0.95 to 1.68$)$ & 0.108 & 0.3 (0.20 to 0.35$)$ & $<0.001$ \\
\hline$\geq 25$ & $25(4.3)$ & $319(1.8)$ & $513(24.3)$ & 2.4 (1.58 to 3.62$)$ & $<0.001$ & 0.1 (0.09 to 0.21$)$ & $<0.001$ \\
\hline Mortality & $12(2.1)$ & $94(0.5)$ & 257 (12.2) & 3.9 (2.10 to 7.08$)$ & $<0.001$ & 0.2 (0.08 to 0.27$)$ & $<0.001$ \\
\hline ISS (aOR) & - & - & - & 3.1 (1.62 to 6.11$)$ & 0.001 & $0.4(0.22$ to 0.79$)$ & 0.007 \\
\hline ISS+age (aOR) & - & - & - & 8.1 (3.99 to 16.43 ) & $<0.001$ & 0.8 (0.40 to 1.47$)$ & 0.431 \\
\hline Hospital LOS (days) & $9.2 \pm 10.1$ & $8.5 \pm 8.8$ & $15.6 \pm 15.9$ & - & 0.093 & - & $<0.001$ \\
\hline ICU stay & $214(36.6)$ & 2360 (13.6) & 1178 (55.7) & 3.7 (3.09 to 4.38 ) & $<0.001$ & 0.5 (0.38 to 0.55$)$ & $<0.001$ \\
\hline ICU LOS (days) & $10.1 \pm 10.2$ & $8.4 \pm 10.6$ & $10.6 \pm 13.0$ & - & 0.024 & - & 0.502 \\
\hline
\end{tabular}

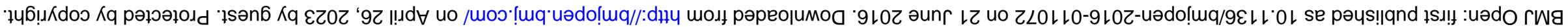


(ISS $\geq 25)$ among regular patients with $\mathrm{RSI}<1$ than among regular patients with $\mathrm{RSI} \geq 1$ (OR 2.4, 95\% CI 1.58 to $3.62 ; \mathrm{p}<0.001)$. Notably, among 585 regular patients with RSI $<1,76(13 \%)$ had SBP $\leq 90 \mathrm{~mm} \mathrm{Hg}$ and $509(87 \%)$ had SBP $>90 \mathrm{~mm} \mathrm{Hg}$, so some of the latter group of patients may not have met the criteria for TTA.

The mortality rates were $2.1 \%, 0.5 \%$ and $12.2 \%$ in regular patients with $\mathrm{RSI}<1$, regular patients with $\mathrm{RSI} \geq 1$ and TTA patients, respectively. A higher mortality rate was noted in regular patients with $\mathrm{RSI}<1$ than in regular patients with $\mathrm{RSI} \geq 1$ (OR 3.9, 95\% CI 2.10 to 7.08; $\mathrm{p}<0.001)$. After adjustment of the OR of mortality for ISS, the mortality rate in regular patients with $\mathrm{RSI}<1$ was 3.1-fold higher $(\mathrm{p}=0.001)$ than that in regular patients with $\mathrm{RSI} \geq 1$, and it was up to 8.1-fold higher $(\mathrm{p}<0.001)$ when the OR was further adjusted for ISS and age. Moreover, the mortality rates in TTA patients were not significantly higher than those in regular patients with $\mathrm{RSI}<1$ after the adjustment for ISS and age (aOR 0.8 , $95 \%$ CI 0.40 to $1.47 ; p=0.431$ ). Further analysis of adult patients (18-65 years of age) (see online supplementary table S1) revealed that the mortality rate in regular patients with $\mathrm{RSI}<1$ was still 4.3-fold higher $(p=0.024)$ than that in regular patients with $\mathrm{RSI} \geq 1$, after adjustment of the OR of mortality for ISS and age. The hospital LOS of regular patients with $\mathrm{RSI}<1$ and regular patients with RSI $\geq 1$ were similar; however, more regular patients with $\mathrm{RSI}<1$ than regular patients with $\mathrm{RSI} \geq 1$ were cared for in the ICU (36.6\% vs $13.6 \%$; OR 3.7, $95 \%$ CI 3.09 to $4.38 ; \mathrm{p}<0.001)$. Furthermore, the ICU LOS in regular patients with $\mathrm{RSI}<1$ was also longer (10.1 vs 8.4 days, $\mathrm{p}=0.024$ ) than that in regular patients with $\mathrm{RSI} \geq 1$, and was similar to that in TTA patients (10.1 vs 10.6 days, $\mathrm{p}=0.502$ ).

The life-saving procedures, including cardiopulmonary resuscitation, intubation, chest tube insertion and blood transfusion, carried out in the ED are summarised in table 2. No regular patients with $\mathrm{RSI}<1$ underwent cardiopulmonary resuscitation. However, 14 (2.4\%), 19 $(3.2 \%)$ and $26(4.4 \%)$ patients received intubation, chest tube insertion and blood transfusion, respectively. In comparison with regular patients with $\mathrm{RSI} \geq 1$, significantly higher rates of intubation, chest tube insertion and blood transfusion were identified in regular patients with $\mathrm{RSI}<1$, although fewer patients received the procedures among regular patients with $\mathrm{RSI}<1$ than among TTA patients. This suggested that patients with $\mathrm{RSI}<1$ may have a greater need for these live-saving procedures despite not meeting the criteria for TTA.

Concerning associated injuries in these trauma patients (table 3), significantly fewer patients had head trauma and maxillofacial trauma among regular patients with $\mathrm{RSI}<1$ than among TTA patients, which may be attributed to a close relationship between intracranial haemorrhage and worsening consciousness, thus leading to a greater possibility of TTA. Regular patients with $\mathrm{RSI}<1$ were also at a greater risk of having a pneumothorax (OR 2.1, 95\% CI 1.21 to $3.63 ; \mathrm{p}=0.017$ ) and haemopneumothorax (OR 3.0, 95\% CI 1.71 to 5.20 ; $\mathrm{p}=0.001$ ) than those with $\mathrm{RSI} \geq 1$. This may explain the higher chest tube insertion rate in regular patients with $\mathrm{RSI}<1$ than in regular patients with $\mathrm{RSI} \geq 1$. Similarly, more regular patients with $\mathrm{RSI}<1$ had intra-abdominal, hepatic, splenic, retroperitoneal and renal injuries than did regular patients with $\mathrm{RSI} \geq 1$. Therefore, regular patients with $\mathrm{RSI}<1$ were more likely to have intra-thoracic or intra-abdominal injuries than regular patients with $\mathrm{RSI} \geq 1$. In addition, there was a higher rate of humeral fracture in regular patients with $\mathrm{RSI}<1$ than in regular patients with $\mathrm{RSI} \geq 1$ (OR 2.6, 95\% CI 2.05 to $3.35 ; \mathrm{p}<0.001)$, whereas the rates of radial and femoral fractures were lower (OR $0.4,95 \%$ CI 0.28 to 0.59 ; $\mathrm{p}<0.001$, and OR $0.6,95 \%$ CI 0.50 to $0.841 ; \mathrm{p}=0.001$, respectively).

\section{DISCUSSION}

The correlation between a high SI and poor outcome has been demonstrated in many previous studies. ${ }^{15}$ 17-20 In this study, RSI was defined as the ratio of SBP to HR, and therefore, theoretically, a lower RSI should correlate with a worse haemodynamic status and a worse outcome. Unsurprisingly, more regular patients with $\mathrm{RSI}<1$ than regular patients with $\mathrm{RSI} \geq 1$ had severe injury. Furthermore, these patients also had a higher mortality rate. After adjusting the OR by controlling for the confounding variables age and ISS, the mortality

Table 2 Life-saving procedures performed in the emergency department

\begin{tabular}{|c|c|c|c|c|c|c|c|}
\hline \multirow[b]{2}{*}{ Variable } & \multirow{2}{*}{$\begin{array}{l}\text { Regular patients } \\
\text { with } R S \mid<1 \\
n=585\end{array}$} & \multirow{2}{*}{$\begin{array}{l}\text { Regular patients } \\
\text { with } \mathrm{RSI} \geq 1 \\
\mathrm{n}=17407\end{array}$} & \multirow{2}{*}{$\begin{array}{l}\text { TTA } \\
\text { patients } \\
\mathrm{n}=2114\end{array}$} & \multicolumn{2}{|c|}{$\begin{array}{l}\text { Regular patients with } \\
\text { RSI<1 vs regular } \\
\text { patients with } \mathrm{RSI} \geq 1\end{array}$} & \multicolumn{2}{|c|}{$\begin{array}{l}\text { Regular patients with } \\
\text { RSI<1 vs TTA patients }\end{array}$} \\
\hline & & & & OR (95\%Cl) & p Value & OR (95\%Cl) & p Value \\
\hline \multicolumn{8}{|c|}{ Procedures in the ED, $\mathrm{n}(\%)$} \\
\hline CPR & $0(0.0)$ & $4(0.0)$ & $24(1.1)$ & - & 1.000 & - & 0.005 \\
\hline Intubation & $14(2.4)$ & $101(0.6)$ & $333(15.8)$ & 4.2 (2.39 to 7.39$)$ & $<0.001$ & 0.1 (0.08 to 0.23$)$ & $<0.001$ \\
\hline $\begin{array}{l}\text { Chest tube } \\
\text { insertion }\end{array}$ & $19(3.2)$ & $140(0.8)$ & $95(4.5)$ & 4.1 (2.55 to 6.73$)$ & $<0.001$ & $0.7(0.43$ to 1.18$)$ & 0.203 \\
\hline $\begin{array}{l}\text { Blood } \\
\text { transfusion }\end{array}$ & $26(4.4)$ & $257(1.5)$ & $292(13.8)$ & 3.1 (2.06 to 4.69$)$ & $<0.001$ & $0.3(0.19$ to 0.44$)$ & $<0.001$ \\
\hline
\end{tabular}


Table 3 Injuries in hospitalised trauma patients

\begin{tabular}{|c|c|c|c|c|c|c|c|}
\hline \multirow[b]{2}{*}{ Variable } & \multirow{2}{*}{$\begin{array}{l}\text { Regular patients } \\
\text { with } R S \mid<1 \\
n=585\end{array}$} & \multirow{2}{*}{$\begin{array}{l}\text { Regular patients } \\
\text { with } R S I \geq 1 \\
n=17407\end{array}$} & \multirow{2}{*}{$\begin{array}{l}\text { TTA patients } \\
\mathrm{n}=2114\end{array}$} & \multicolumn{2}{|c|}{$\begin{array}{l}\text { Regular patients with } R S \mid<1 \\
\text { vs regular patients with } \\
\text { RSI } \geq 1\end{array}$} & \multicolumn{2}{|c|}{$\begin{array}{l}\text { Regular patients with } R S \mid<1 \\
\text { vs TTA patients }\end{array}$} \\
\hline & & & & OR (95\% Cl) & p Value & OR (95\% Cl) & p Value \\
\hline \multicolumn{8}{|l|}{ Head trauma, n (\%) } \\
\hline Neurological deficit & $0(0.0)$ & $72(0.4)$ & $46(2.2)$ & - & 0.177 & - & $<0.001$ \\
\hline Cranial fracture & $31(5.3)$ & $599(3.4)$ & $440(20.8)$ & 1.6 (1.08 to 2.28$)$ & 0.018 & $0.2(0.15$ to 0.31$)$ & $<0.001$ \\
\hline Epidural haematoma (EDH) & $16(2.7)$ & $381(2.2)$ & $323(15.3)$ & $1.3(0.78$ to 2.09$)$ & 0.388 & $0.2(0.10$ to 0.26$)$ & $<0.001$ \\
\hline Subdural haematoma (SDH) & $28(4.8)$ & $1015(5.8)$ & $664(31.4)$ & $0.8(0.55$ to 1.19$)$ & 0.322 & $0.1(0.07$ to 0.16$)$ & $<0.001$ \\
\hline Subarachnoid haemorrhage (SAH) & $29(5.0)$ & $965(5.5)$ & $617(29.2)$ & 0.9 (0.61 to 1.30$)$ & 0.638 & $0.1(0.09$ to 0.19$)$ & $<0.001$ \\
\hline Intracerebral haematoma (ICH) & $4(0.7)$ & $193(1.1)$ & $181(8.6)$ & $0.6(0.23$ to 1.66$)$ & 0.421 & $0.1(0.03$ to 0.20$)$ & $<0.001$ \\
\hline Cerebral contusion & $16(2.7)$ & $503(2.9)$ & $369(17.5)$ & $0.9(0.57$ to 1.57$)$ & 0.985 & 0.1 (0.08 to 0.22$)$ & $<0.001$ \\
\hline Cervical vertebral fracture & $3(0.5)$ & $116(0.7)$ & $40(1.9)$ & 0.8 (0.24 to 2.42$)$ & 1.000 & $0.3(0.08$ to 0.87$)$ & 0.015 \\
\hline \multicolumn{8}{|l|}{ Maxillofacial trauma, $\mathrm{n}(\%)$} \\
\hline Orbital fracture & $1(0.2)$ & $272(1.6)$ & $53(2.5)$ & 0.1 (0.02 to 0.77$)$ & 0.003 & 0.1 (0.01 to 0.48$)$ & $<0.001$ \\
\hline Nasal fracture & $3(0.5)$ & $149(0.9)$ & $38(1.8)$ & $0.6(0.19$ to 1.88$)$ & 0.494 & 0.3 (0.09 to 0.92$)$ & 0.021 \\
\hline Maxillary fracture & $8(1.4)$ & $775(4.5)$ & $242(11.4)$ & $0.3(0.15$ to 0.60$)$ & $<0.001$ & 0.1 (0.05 to 0.22$)$ & $<0.001$ \\
\hline Mandibular fracture & $8(1.4)$ & $314(1.8)$ & $85(4.0)$ & 0.8 (0.37 to 1.53$)$ & 0.527 & 0.3 (0.16 to 0.69$)$ & 0.001 \\
\hline \multicolumn{8}{|l|}{ Thoracic trauma, $n(\%)$} \\
\hline Rib fracture & $26(4.4)$ & $1193(6.9)$ & $252(11.9)$ & 0.6 (0.43 to 0.94$)$ & 0.027 & 0.3 (0.23 to 0.52$)$ & $<0.001$ \\
\hline Sternal fracture & $0(0.0)$ & $19(0.1)$ & $7(0.7)$ & - & 1.000 & - & 0.358 \\
\hline Haemothorax & $7(1.2)$ & $169(1.0)$ & $87(4.1)$ & 1.2 (0.58 to 2.64$)$ & 0.520 & $0.3(0.13$ to 0.61$)$ & $<0.001$ \\
\hline Pneumothorax & $14(2.4)$ & $201(1.2)$ & $81(3.8)$ & 2.1 (1.21 to 3.63$)$ & 0.017 & 0.6 (0.35 to 1.09$)$ & 0.100 \\
\hline Haemopneumothorax & $14(2.4)$ & $142(0.8)$ & $81(3.8)$ & $3.0(1.71$ to 5.20$)$ & 0.001 & $0.6(0.35$ to 1.09$)$ & 0.100 \\
\hline Lung contusion & $8(1.4)$ & $111(0.6)$ & $80(3.8)$ & $2.2(1.05$ to 4.45$)$ & 0.060 & $0.4(0.17$ to 0.73$)$ & 0.002 \\
\hline Thoracic vertebral fracture & $4(0.7)$ & $150(0.9)$ & $42(2.0)$ & $0.8(0.29$ to 2.15$)$ & 0.821 & $0.3(0.12$ to 0.95$)$ & 0.030 \\
\hline \multicolumn{8}{|l|}{ Abdominal trauma, $\mathrm{n}(\%)$} \\
\hline Intra-abdominal injury & $16(2.7)$ & $197(1.1)$ & $101(4.8)$ & 2.5 (1.47 to 4.12$)$ & 0.003 & $0.6(0.33$ to 0.96$)$ & 0.030 \\
\hline Hepatic injury & $26(4.4)$ & $187(1.1)$ & $113(5.3)$ & $4.3(2.82$ to 6.51$)$ & $<0.001$ & 0.8 (0.53 to 1.27$)$ & 0.459 \\
\hline Splenic injury & $12(2.1)$ & $106(0.6)$ & $64(3.0)$ & 3.4 (1.87 to 6.25$)$ & $<0.001$ & 0.7 (0.36 to 1.25$)$ & 0.258 \\
\hline Retroperitoneal injury & $3(0.5)$ & $14(0.1)$ & $12(0.6)$ & 6.4 (1.84 to 22.35 ) & 0.017 & $0.9(0.25$ to 3.21$)$ & 1.000 \\
\hline Renal injury & $6(1.0)$ & $60(0.3)$ & $25(1.2)$ & $3.0(1.29$ to 6.96$)$ & 0.020 & 0.9 (0.35 to 2.12$)$ & 1.000 \\
\hline Urinary bladder injury & $0(0.0)$ & $24(0.1)$ & $7(0.3)$ & - & 1.000 & - & 0.358 \\
\hline Lumbar vertebral fracture & $7(1.2)$ & $297(1.7)$ & $44(2.1)$ & 0.7 (0.33 to 1.48$)$ & 0.417 & 0.6 (0.26 to 1.27$)$ & 0.228 \\
\hline Sacral vertebral fracture & $3(0.5)$ & $79(0.5)$ & $20(0.9)$ & $1.1(0.36$ to 3.59$)$ & 0.750 & 0.5 (0.16 to 1.82$)$ & 0.447 \\
\hline \multicolumn{8}{|l|}{ Extremity trauma, n (\%) } \\
\hline Scapular fracture & $6(1.0)$ & $229(1.3)$ & $42(2.0)$ & 0.8 (0.34 to 1.76$)$ & 0.710 & $0.5(0.22$ to 1.21$)$ & 0.156 \\
\hline Clavicle fracture & $18(3.1)$ & $1141(6.6)$ & $185(8.8)$ & 0.5 (0.28 to 0.73$)$ & 0.001 & $0.3(0.20$ to 0.54$)$ & $<0.001$ \\
\hline
\end{tabular}




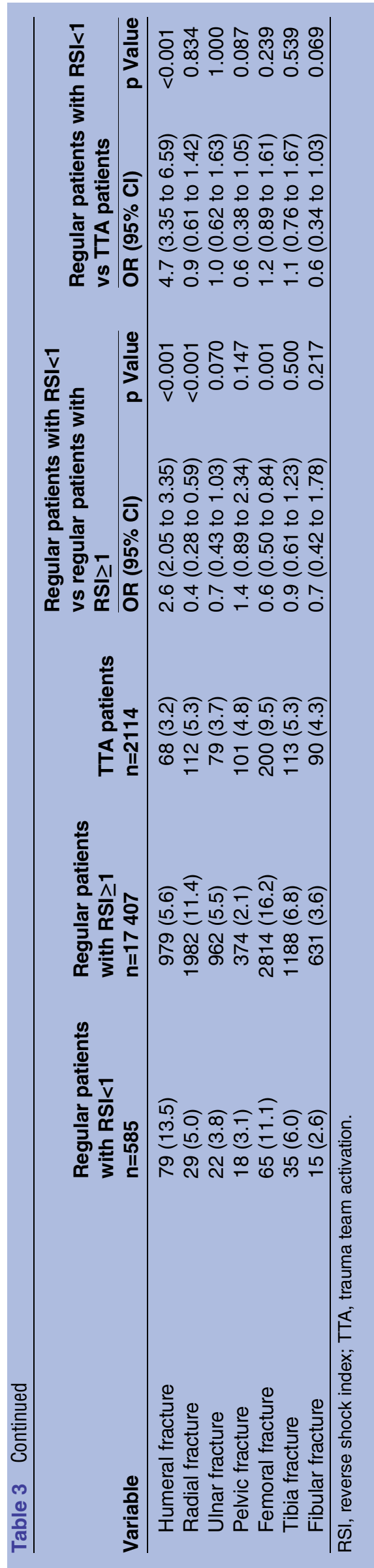

rate rose even higher for regular patients with $\mathrm{RSI}<1$, which was the same as that for TTA patients. A higher rate of ICU stay, a longer ICU LOS, and more life-saving procedures were also seen in this population than in regular patients with $\mathrm{RSI} \geq 1$. This result suggested that a decreasing RSI indicates an unstable haemodynamic status and an injury that can be life threatening.

In this study, regular patients with $\mathrm{RSI}<1$ were not associated with a higher percentage of head trauma or maxillofacial trauma than were regular patients with $\mathrm{RSI} \geq 1$. There is a lack of information on the relationship between head injuries and unstable haemodynamic status; however, head injury as a cause of shock in paediatric patients has been reported previously. ${ }^{22}$ Another study stated that the relationship between SI and haemorrhage is altered after an acute traumatic brain injury, and that the use of SI in the assessment of blood volume loss could be unreliable in these patients. ${ }^{23}$ Thoracic and abdominal traumas, on the other hand, often result in massive haemorrhage, which subsequently leads to haemodynamic instability. Therefore, more regular patients with $\mathrm{RSI}<1$ and TTA patients have thoracic trauma and abdominal trauma than do regular patients with $\mathrm{RSI} \geq 1$. Notably, in addition to SI, a paediatric specific SI has also been reported in the literature. ${ }^{24}$ In our study, patients $<9$ years of age account for $59.5 \%$ of the total population of regular patients with $\mathrm{RSI}<1$. This makes sense because, physiologically, children have higher HRs than adults. A systematic review by Fleming et $a l^{25}$ demonstrated a decline in HR with age, and that the median HR decreases to $100 \mathrm{bpm}$ between 4 and 6 years of age. Therefore, an even worse outcome for patients with $\mathrm{RSI}<1$ can be expected if children, the so-called normal variants in this study, were excluded. In this study, the mortality rate in regular adult patients with $\mathrm{RSI}<1$ was still 4 .3-fold higher than that in regular adult patients with $\mathrm{RSI} \geq 1$, after adjustment of the OR of mortality for ISS and age.

Should $\mathrm{RSI}<1$ be added as a criterion for TTA? TTA is used to identify and provide rapid treatment for the most severely injured trauma patients, and there is a tendency to overtriage to prevent mortality or morbidity due to delays in definitive care. However, overtriage affects the efficiency of care and can result in increased costs, inappropriate resource use, and frustration for the care provider. ${ }^{26}$ In our study, the mortality of regular patients with $\mathrm{RSI}<1$ was significantly higher than that of regular patients with $\mathrm{RSI} \geq 1$. The rate for very severe injuries (ISS $\geq 25$ ), ICU stay, ICU LOS, rates of life-saving procedures in the $\mathrm{ED}$, and proportions of thoracic/ abdominal trauma are also higher or longer, respectively. However, comparison of these variables between regular patients with $\mathrm{RSI}<1$ and TTA patients shows that injury severity, hospital LOS and proportion of patients admitted to the ICU were lower for regular patients with $\mathrm{RSI}<1$; however, the mortality rate was similar after adjustment for ISS and age. Notably, $87 \%$ of regular patients with $\mathrm{RSI}<1$ had $\mathrm{SBP}>90 \mathrm{~mm} \mathrm{Hg}$ and may not 
have met the criteria for TTA. Therefore, if $\mathrm{RSI}<1$ were added to the criteria for TTA due to concerns about mortality, it would result in overtriage in the ED in relation to most other outcome measurements.

This study has some limitations. First, the retrospective study design may have given rise to possible bias. Second, the study population was limited to a single urban trauma centre in southern Taiwan. Furthermore, bias may have resulted from the fact that injured patients who died before hospital arrival or who were discharged against advice from the ED were not included in the sample. In addition, there was a lack of available data about the circumstances of injury and the factors influencing decisions concerning patient management. Lastly, other important data such as underlying diseases (eg, hypertension, chronic obstructive pulmonary disease, asthma, etc), medication use (eg, $\beta$ blockers or $\beta$ agonists), costs, delays in treatment, and complications were not evaluated in this study.

\section{CONCLUSION}

Our examination of data on trauma admissions at a level I trauma centre showed that among patients who did not meet the criteria for TTA, RSI $<1$ was associated with more life-saving procedures in the ED, a higher ICU admission rate, a longer ICU stay, and a higher mortality rate. Because these patients are potentially at risk of lifethreatening problems, they should receive more attention and aggressive care in the ED.

\section{Author affiliations}

${ }^{1}$ Department of Trauma Surgery, Kaohsiung Chang Gung Memorial Hospital and Chang Gung University College of Medicine, Kaohsiung, Taiwan ${ }^{2}$ Department of Surgery, Kaohsiung Chang Gung Memorial Hospital and Chang Gung University College of Medicine, Kaohsiung, Taiwan ${ }^{3}$ Department of Plastic and Reconstructive Surgery, Kaohsiung Chang Gung Memorial Hospital and Chang Gung University College of Medicine, Kaohsiung, Taiwan

${ }^{4}$ Department of Neurosurgery, Kaohsiung Chang Gung Memorial Hospital and Chang Gung University College of Medicine, Kaohsiung, Taiwan

Contributors SCHK wrote the manuscript; P-JK contributed to analysis of the data; $\mathrm{S}-\mathrm{YH}$ collected the data and performed the statistical analyses; $\mathrm{Y}$-CC edited the tables; $\mathrm{H}-\mathrm{YH}$ revised the English and proofread the manuscript; and $\mathrm{C}-\mathrm{HH}$ designed the study, contributed to the analysis and interpretation of data, and drafted the manuscript. All authors read and approved the final manuscript.

Funding This research was supported by a grant from Chang Gung Memorial Hospital (CDRPG8C0032 and CDRPG8C0033).

Competing interests None declared.

Provenance and peer review Not commissioned; externally peer reviewed.

Data sharing statement No additional data are available.

Open Access This is an Open Access article distributed in accordance with the Creative Commons Attribution Non Commercial (CC BY-NC 4.0) license, which permits others to distribute, remix, adapt, build upon this work noncommercially, and license their derivative works on different terms, provided the original work is properly cited and the use is non-commercial. See: http:// creativecommons.org/licenses/by-nc/4.0/

\section{REFERENCES}

1. Lehmann R, Brounts L, Lesperance $\mathrm{K}$, et al. A simplified set of trauma triage criteria to safely reduce overtriage: a prospective study. Arch Surg 2009;144:853-8.

2. Ruger JP, Lewis LM, Richter CJ. Identifying high-risk patients for triage and resource allocation in the ED. Am J Emerg Med 2007;25:794-8.

3. van Laarhoven JJ, Lansink KW, van Heijl M, et al. Accuracy of the field triage protocol in selecting severely injured patients after high energy trauma. Injury 2014;45:869-73

4. Deane SA, Gaudry PL, Pearson I, et al. The hospital trauma team: a model for trauma management. J Trauma 1990;30: 806-12.

5. Adedeji OA, Driscoll PA. The trauma team-a system of initial trauma care. Postgrad Med J 1996;72:587-93.

6. Egberink RE, Otten HJ, IJzerman MJ, et al. Trauma team activation varies across Dutch emergency departments: a national survey. Scand J Trauma Resusc Emerg Med 2015;23:100.

7. Georgiou A, Lockey DJ. The performance and assessment of hospital trauma teams. Scand J Trauma Resusc Emerg Med 2010;18:66.

8. DeMuro JP, Simmons S, Jax J, et al. Application of the Shock Index to the prediction of need for hemostasis intervention. Am J Emerg Med 2013;31:1260-3.

9. Demetriades D, Chan LS, Bhasin P, et al. Relative bradycardia in patients with traumatic hypotension. J Trauma 1998;45:534-9.

10. Ley EJ, Salim A, Kohanzadeh S, et al. Relative bradycardia in hypotensive trauma patients: a reappraisal. J Trauma 2009;67:1051-4.

11. Luna GK, Eddy AC, Copass M. The sensitivity of vital signs in identifying major thoracoabdominal hemorrhage. Am J Surg 1989;157:512-15.

12. Thompson D, Adams SL, Barrett J. Relative bradycardia in patients with isolated penetrating abdominal trauma and isolated extremity trauma. Ann Emerg Med 1990;19:268-75.

13. Pandit V, Rhee $\mathrm{P}$, Hashmi $\mathrm{A}$, et al. Shock index predicts mortality in geriatric trauma patients: an analysis of the National Trauma Data Bank. J Trauma Acute Care Surg 2014;76:1111-15.

14. Bruijns SR, Guly HR, Bouamra O, et al. The value of traditional vital signs, shock index, and age-based markers in predicting trauma mortality. J Trauma Acute Care Surg 2013;74:1432-7.

15. McNab A, Burns B, Bhullar I, et al. A prehospital shock index for trauma correlates with measures of hospital resource use and mortality. Surgery 2012;152:473-6.

16. Birkhahn RH, Gaeta TJ, Terry D, et al. Shock index in diagnosing early acute hypovolemia. Am J Emerg Med 2005;23:323-6.

17. Cannon CM, Braxton CC, Kling-Smith M, et al. Utility of the shock index in predicting mortality in traumatically injured patients. J Trauma 2009;67:1426-30.

18. Mitra B, Fitzgerald M, Chan J. The utility of a shock index $\geq 1$ as an indication for pre-hospital oxygen carrier administration in major trauma. Injury 2014:45:61-5.

19. Talmor $D$, Jones $A E$, Rubinson $L$, et al. Simple triage scoring system predicting death and the need for critical care resources for use during epidemics. Crit Care Med 2007;35:1251-6.

20. Mutschler M, Nienaber U, Munzberg M, et al. TraumaRegister DGU. The Shock Index revisited-a fast guide to transfusion requirement? A retrospective analysis on 21,853 patients derived from the TraumaRegister DGU. Crit Care 2013;17:R172.

21. Chuang JF, Rau CS, Wu SC, et al. Use of the reverse shock index for identifying high-risk patients in a five-level triage system. Scand $J$ Trauma Resusc Emerg Med 2016;24:12.

22. Gardner A, Poehling KA, Miller CD, et al. Isolated head injury is a cause of shock in pediatric trauma patients. Pediatr Emerg Care 2013;29:879-83.

23. McMahon CG, Kenny R, Bennett K, et al. The effect of acute traumatic brain injury on the performance of shock index. $J$ Trauma 2010;69:1169-75.

24. Acker SN, Ross JT, Partrick DA, et al. Pediatric specific shock index accurately identifies severely injured children. J Pediatr Surg 2015;50:331-4.

25. Fleming S, Thompson M, Stevens R, et al. Normal ranges of heart rate and respiratory rate in children from birth to 18 years of age: a systematic review of observational studies. Lancet 2011;377:1011-18

26. Lehmann RK, Arthurs ZM, Cuadrado DG, et al. Trauma team activation: simplified criteria safely reduces overtriage. Am J Surg 2007;193:630-4; discussion 34-5 